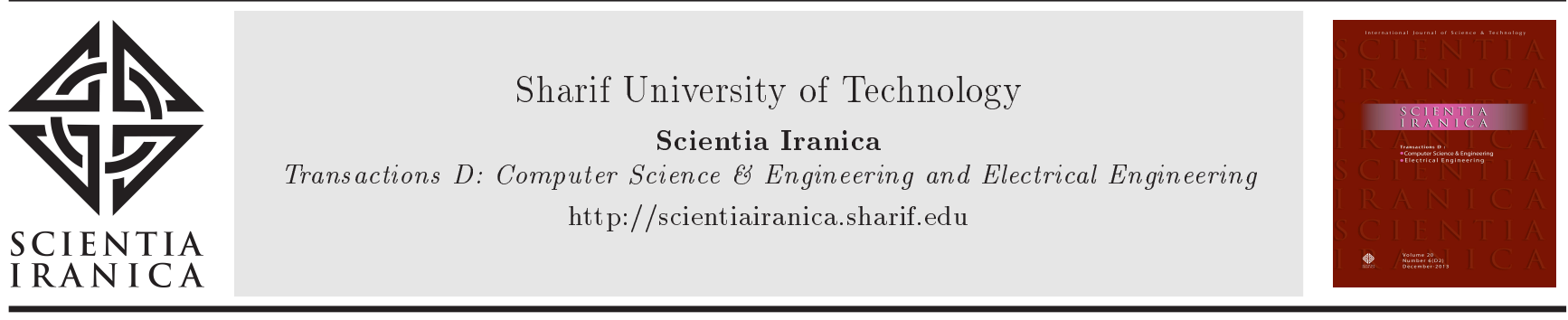

\title{
A dual-stator machine with diametrically magnetized PM: Analytical air-gap flux calculation, efficiency optimization, and comparison with conventional dual-stator machines
}

\author{
Sh. Asgari ${ }^{a, *}$, R. Yazdanpanah ${ }^{\mathrm{b}}$, and M. Mirsalim ${ }^{\mathrm{a}}$ \\ a. Laboratory of Electrical Machines and Transformers Research, Department of Electrical Engineering, Amirkabir University of \\ Technology, Tehran, P.O. Box 1591634311, Iran. \\ b. Department of Electrical Engineering, University of Larestan, Lar, Iran.
}

Received 12 April 2019; received in revised form 8 August 2019; accepted 2 September 2019

KEYWORDS
Analytical design;
Dual-stator;
Finite element
method;
Optimization;
PM machine;
Torque.

\section{Introduction}

Permanent Magnet Synchronous Machines (PMSMs) have been investigated for various requests such as industrial, transportation, renewable energy, and directdrive applications due to their high torque density, high power density, high power factor, and efficiency [13]. Because of better utilization of materials and high

\footnotetext{
*. Corresponding author.

E-mail addresses: asgari_shahin@aut.ac.ir (Sh. Asgari); ryazdanpanah@lar.ac.ir (R. Yazdanpanah); mirsalim@aut.ac.ir (M. Mirsalim)
}

\begin{abstract}
This paper presents a design and optimization procedure for a dual-stator machine with a diametrically magnetized PM to improve the electromagnetic performance. First, analytical design equations are presented based on MEC analysis; they are used to machine. Then, by applying an artificial intelligence algorithm, he machine is optimized to achieve high efficiency and torque density as well as low pulsating torque for direct-drive applications. A quantitative comparison is performed performances and improvements of the understudy machine. The machine performances ncluding air-gap flux density distribution, back electromotive force, electromagnetic cogging torque, and torque ripple are analyzed using the finite element method. The analysis results have demonstrated that benefiting from its topology, the optimized dual-stator machine with a diametrically magnetized PM has comprehensively better nd cogging torque compared to conventional dual-stator machines.
\end{abstract}

C) 2022 Sharif University of Technology. All rights reserved.

\footnotetext{
(1: $10.24200 /$ sci. 2019.53316 .3181
}

performance, three-phase PMSMs are the most common for the mentioned applications [1]. The dual airgap PMSMs including Dual-Stator PM Synchronous Machines (DS-PMSM) [4-7] and dual-rotor PM machines [8-11] offer a higher power density than the conventional ones because of the total output torque resulting from the torque components produced by the interactions between two air-gap flux densities.

Lately, various DS-PMSM machines are being researched $[1,12-16]$ that provide better performances over the previously introduced machines. Spoke-type electrical machines have been found useful because of their enhanced torque density and flux focusing effects. A Dual-Stator Spoke-Type Vernier Machine (DSSTVM) realizes a flux-focusing effect on Vernier 
machines and so, achieves a high value of power factor. However, DSSTVM only focuses on this factor for the Vernier machine. In [17,18], high-temperature superconductor bulks were utilized in the PM Vernier machine to shield against the leakage flux and increase the torque density.

Also, cogging torque is one of the primary drawbacks of PMSMs, especially for low-speed and directdrive applications leading to vibration and acoustic noise [19].

A novel topology for DS-PMSM was introduced in [4]. In this paper, first, an analytical model for air-gap flux density calculation in a variable thickness DS-PMSM was presented and verified by a numerical method. This model could be used for the primary design objectives. Then, the structure optimization was investigated to determine the appropriate motor for high torque and low-speed applications.

A comparative study of the new proposed DSPMSM [4] and previously researched machines is performed for high torque and low-speed applications, where the critical parameters are torque ripple, cogging torque, torque density, and efficiency. To disclose the characteristics, the Finite Element Method (FEM) analysis is used.

\section{Machine topology and field calculations}

Figure 1 shows a dual-stator permanent magnet synchronous machine with Diametrically Magnetized Cylindrical PMs (DMCPMs) that is an alternative to a DS-PMSM with surface mounted PMs and has the following advantages [4]:

- Higher mechanical strength;

- Lower torque ripple;

- Sinusoidal air-gap flux density distribution;

- Less construction cost.

Figure 2 shows that the inner stator flux crosses the air-gap and the PM and then, enters the outer stator before closing the path in the adjacent pole.

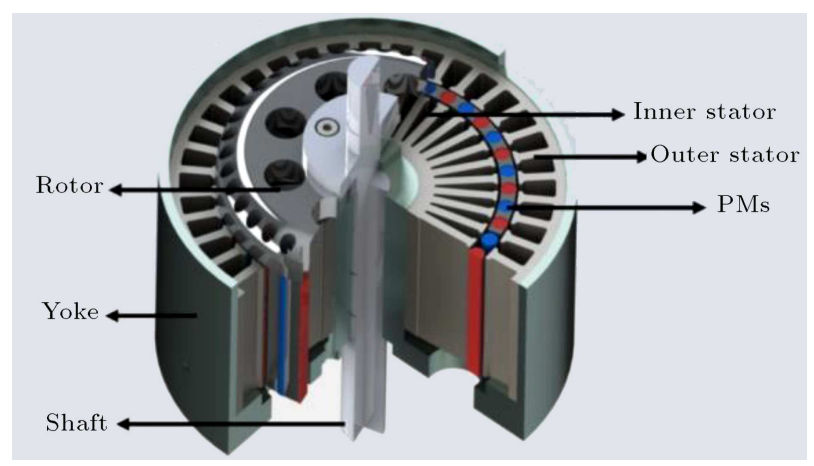

Figure 1. DMCPM 3D structure.

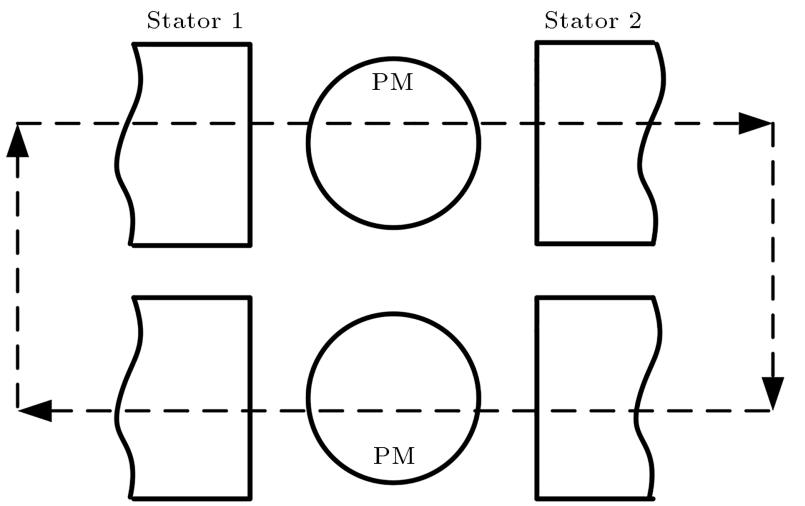

Figure 2. Flux path in stator and rotor.

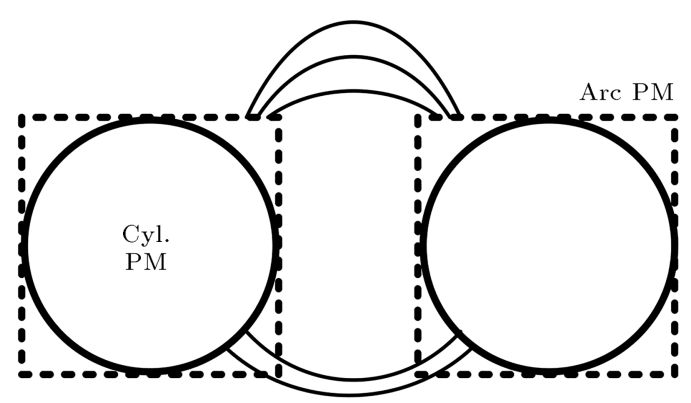

Figure 3. Leakage flux at the edge and center of PM.

A smaller thickness at the edges compared to the centre of a PM results in a lower tooth torque and the PM leakage flux [4] (Figure 3).

\subsection{Air-gap flux density calculation using $M E C$}

The variable PM thickness changes the trapezoidal flux density distribution into a sinusoidal. In most models of the Magnetic Equivalent Circuit (MEC) for PM machines, the PM is represented by a flux source and a reluctance [20]. Because of the varying PM thicknesses, such models are not accurate enough to determine the air-gap flux density distribution.

Therefore, a new approach will be proposed in this section for these structures and the results will be compared using the FEM analysis results.

Figure 4 shows one pole pair of the machine, where $R_{s}, R_{l}, \phi_{r}$, and $R_{m}$ are the stator reluctance, leakage flux path reluctance, flux source, and the PM reluctance, respectively. The simplified MEC is given in Figure 5(a), where the PM flux, air-gap flux, and leakage flux are denoted by $\phi, \phi_{g}$, and $\phi_{l}$, respectively.

It is not easy to determine an analytical equation for the leakage reluctance, but the air gap flux can be written in terms of the magnetic flux as $\varphi_{g}=K_{l} \varphi$ where $K_{l}$ is a leakage factor that is typically a little less than one. In other words, the leakage reluctance can be eliminated by using this relationship. For the motor with surface PMs, the leakage factor is typically in the range of $0.9<K_{l} \leq 1$. Because of the 


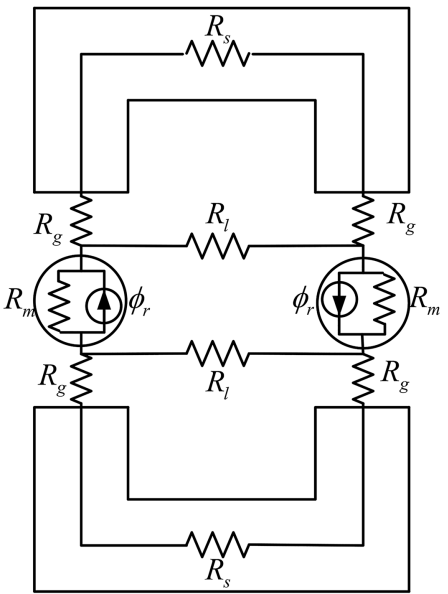

Figure 4. One pole pair of the machine MEC.
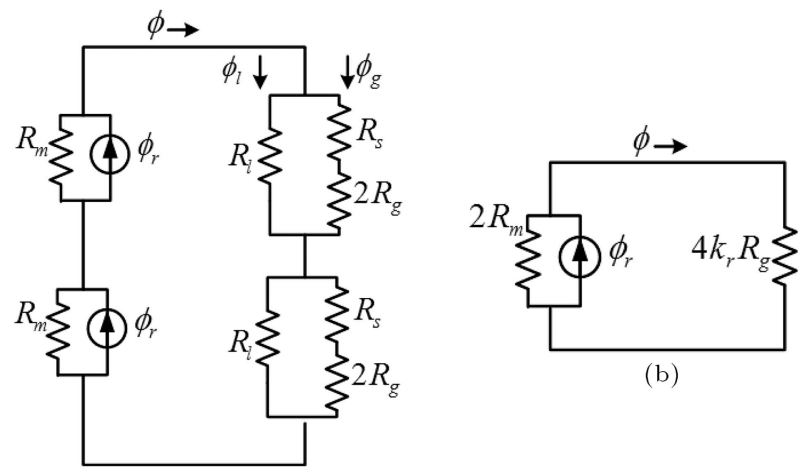

(b)

(a)

Figure 5. Simplified MEC: (a) First simplification and (b) final.

saturation characteristic of ferromagnetic materials, the steel reluctance $\left(R_{s}\right)$ is nonlinear. Therefore, this reluctance must be eliminated in some way to find an analytical solution. As the permeability of the steel is high, the steel reluctance is smaller than the air gap reluctance $R_{g}$. That is, the steel reluctance can be eliminated by introducing a reluctance factor $K_{r}$. Here, $K_{r}$ is a constant that slightly increases the air gap reluctance; thus, steel reluctance is considered. The reluctance factor is in the range of $1.0<K_{r} \leq 1.2$ [20].

It is important to note that determining an accurate analytical expression for the leakage and reluctance factors complicates the proposed model. These values are usually chosen based on the experience. Therefore, in this study, the mean value of their ranges is selected to simplify the proposed model $\left(K_{l}=0.95\right.$, $K_{r}=1.1$ ). Final simplified MEC results are shown in Figure 5(b).

\section{2. $M E C$ calculations}

As given in Figure 5, the flux is calculated by:

$$
\phi=\frac{2 R_{m}}{2 R_{m}+4 k_{r} R_{g}} \phi_{r}=\frac{1}{1+2 k_{r} R_{g} / R_{m}} \phi_{r} .
$$

Considering:

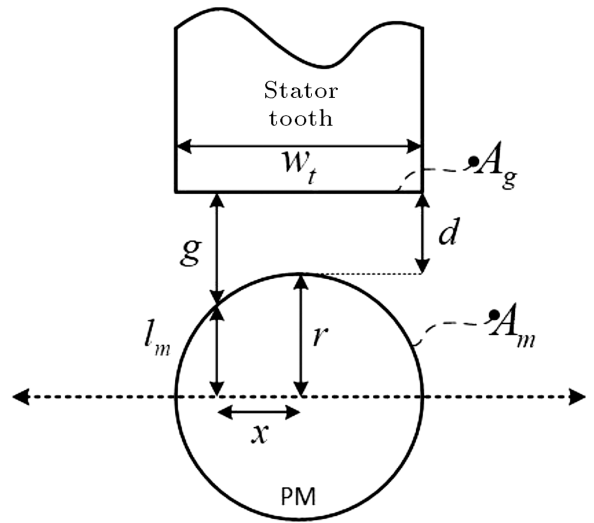

Figure 6. The PM and stator tooth in a PM machine with variable thickness.

$$
R_{m}=\frac{l_{m}}{\mu_{r} \mu_{0} A_{m}}, \quad R_{g}=\frac{g}{\mu_{0} A_{g}},
$$

results in:

$$
\phi_{g}=k_{l} \phi=\frac{k_{l}}{1+2 k_{r} \frac{\mu_{r} g A_{m}}{l_{m} A_{g}}} \phi_{r}
$$

where $A_{m}, l_{m}, g$, and $A_{g}$ are the PM cross-section area, thickness, the air-gap length, and cross-section area, respectively. Using:

$$
B_{g}=\frac{\phi_{g}}{A_{g}}, \quad B_{r}=\frac{\phi_{r}}{A_{m}}, \quad c=\frac{A_{m}}{A_{g}}, \quad p=\frac{l_{m}}{g \cdot c},
$$

the air-gap flux density is:

$$
B_{g}(x)=\frac{k_{l} c}{1+2 k_{r} \frac{\mu_{r}}{p}} B_{r} .
$$

The PM to air-gap area coefficient, or flux concentration factor $c$, is equal to 1 for surface mounted PM machines [20]. For the current topology with a stack length of $L$ and considering Figure 6 , it is calculated as follows:

$$
A_{m}=r \pi L, \quad A_{g}=w_{t} L \rightarrow c=\frac{r \pi}{w_{t}} .
$$

In addition, the effect of open slots of the stator is handled by the Carter coefficient. In other words, the real air gap is replaced by an equivalent air gap [21].

For the PM machine with variable thickness shown in Figure 6, the corresponding air-gap length and PM thickness are related to each other as in Eq. (7). This equation is used in Eq. (5) to calculate the air-gap flux density at each point.

$$
\begin{aligned}
l_{m}(x) & =\sqrt{r^{2}-x^{2}}, \quad g(x)=r+d-l_{m}(x) ; \\
-r & \leq x \leq r .
\end{aligned}
$$

\subsection{Flux density distribution verification and machine dimensions}

Using Eq. (5), for a basic machine, the air-gap flux density distribution results are shown in Figure 7 . This 




Figure 7. The air-gap flux density distribution.

figure also compares the analytical results with the numerical field calculations by FEM that verifies the accuracy of the proposed analytical method. Also, the peak flux density calculated by the MEC is exactly coincident with the numerical analysis. The discrepancy in the two ends of the magnetic flux density distribution is due to the flux fringing effect, as the proposed model simplifies the magnetic circuit to reduce the calculations.

If the machine is designed to have no saturation at critical points, linear behavior in the whole range of operations would be achieved. Therefore, the average magnetic flux density at the mentioned points that are inner and outer stators is calculated as follows:

$$
B_{\text {sat.s }}=\frac{\phi_{g}}{l_{s} L} .
$$

Here, $l_{s}$ and $L$ are the yoke thickness and the machine axial length of the stators, respectively. In the design process, $B_{\text {sat.s }}$ should be kept below the saturation point.

\section{Machine design and optimization}

\subsection{Design algorithm}

In this subsection, the design algorithm is explained step by step. Figure 8 depicts the flowchart of the design process with the main values tabulated in Table 1.

\subsubsection{Design criteria}

There are some specific constraints for design of electric machines in every application. The maximum current density, the maximum flux densities in the teeth and the yoke, and the maximum temperature are some of the most important limitations. In the first step, the required design specifications for the proposed machine should be determined. Here, the design variables are chosen as the radii of the inner and outer air-gap, the number of slots, and the pole-arc to pole-pitch ratio. The final values are given in Table 1.

\subsubsection{Number of poles and the pole-arc width}

The length of pole-arc is the main difficulty in using DMCPMs for designing DS-PMSMs, especially in the

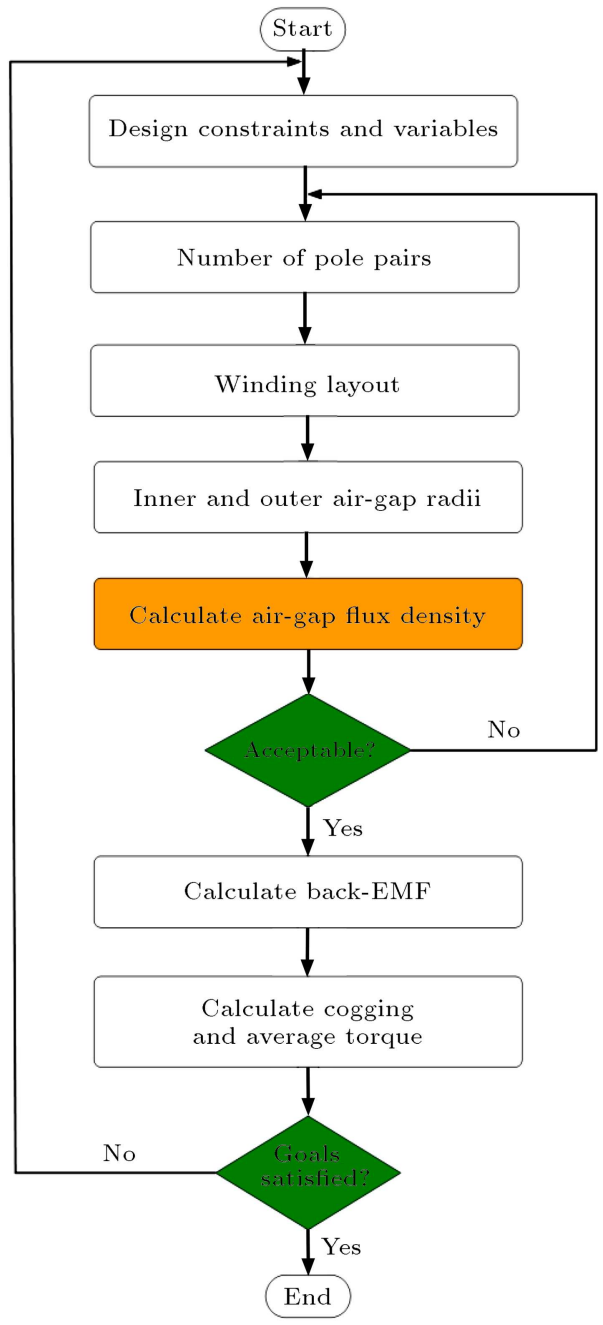

Figure 8. The design process flowchart for DMCPMs.

Table 1. The main geometric and electromagnetic parameters of the machine.

\begin{tabular}{clc}
\hline Symbol & \multicolumn{1}{c}{ Parameter } & Value \\
\hline- & Phase & 3 \\
- & Slot/pole & $36 / 38$ \\
$O_{D}$ & Motor outer diameter $(\mathrm{mm})$ & 133 \\
$I_{D}$ & Motor inner diameter $(\mathrm{mm})$ & 44 \\
$d$ & Minimum air-gap length $(\mathrm{mm})$ & 0.7 \\
$J$ & Current density $\left(\mathrm{A} / \mathrm{mm}^{2}\right)$ & 5.5 \\
$B_{r}$ & PM remanence $(\mathrm{T})$ & 1.28 \\
$L$ & Axial length $(\mathrm{mm})$ & 60 \\
$P_{n}$ & Power @750 rpm (watt) & 1400 \\
$\mathrm{r}$ & PM radius (mm) & 5.5 \\
$K_{w}$ & Slot fill factor $(\%)$ & 50 \\
$N$ & Number of turns of coils & 38 \\
\hline
\end{tabular}

small number of pole-pair structures. As Figure 2 shows, increasing the pole-arc results in higher thickness of PMs. To overcome this, one approach is to increase the number of poles that decreases the 
mechanical pole-arc angle. Here, according to the maximum speed of the application and the width of the pole-arc, the number of poles is selected.

\subsubsection{Slot width, combinations of the numbers of slots and poles, and winding layout}

Based on the results presented in Section two, it can be concluded that the highest amount of reduction in the cogging torque appears where the diameter of the PM is equal to, or smaller than, the width of the tooth [4]. The appropriate diameter of the PM can be realized by using the fractional slot structure with the number of slots per-pole per-phase less than unity $(q<1)$.

Eq. (9) shows the cogging torque goodness factor:

$$
C=\frac{2 P N_{s}}{N_{c}},
$$

where if $C$ is small, the cogging torque is low [22]. Here, $P$ is the number of pole pairs, $N_{s}$ the number of slots, and $N_{C}$ the smallest common multiplier of numbers of slots and numbers of poles. In general, there are two types of winding configuration: distributed and concentrated. The concentrated winding is more appropriate for this structure due to its advantages [23]:

- Fractional slot structure;

- Slots per-pole per-phase less than unity $(q<1)$;

- High power and efficiency;

- Short end winding and consequently, less copper loss;

- Increased torque to current ratio due to the high slot fill factor.

It should be noted that the concentrated winding produces harmonics in the air-gap magneto-motive force (mmf) that increases iron loss in the rotor, especially in non-laminated structures. Here, due to the use of aluminum in the structure of the proposed rotor, the iron losses of the rotor are neglected.

\subsubsection{The air-gap radii and flux density}

The design algorithm has a loop for the number of poles, the air-gap radius, the air-gap flux density, and the PM thickness and it is used to calculate the inner and outer air-gap radii. Air-gap flux density is calculated using the 2 nd section equations. It should be mentioned that this algorithm is not suitable for the low-pole structures with the number of poles smaller than 12 .

\subsubsection{Back-EMF and torque characteristics}

After satisfying the air-gap flux density, the primary machine characteristics including the cogging torque, torque ripple, the average torque, and the efficiency are calculated. If the results are acceptable, the process will be finished. If not, the process will go back to the first step, and the design constraints will be changed within the allowable range until the design goals are satisfied.

\subsection{Optimization approach}

For high torque and low-speed applications, the essential characteristics are air-gap flux density, back EMF, torque density, efficiency, and losses. Dual-stator machines inherently have a higher torque density than single-stator machines as the produced torque is the sum of the two air-gap torques.

The principal objective of the DMCPM optimization is machine efficiency, but the cogging torque and torque ripple and density are considered as the constraints in this process.

The primary design parameter that affects the machine performance is the rotor radius. This parameter determines the rotor position between the two stators. For a constant PM radius, the rotor radius defines the ratio of PM arc to pole arc $(\alpha)$ that affects the torque ripple and cogging torque directly [24].

In the machine under study, the magnetic circuits of inner and outer stators are in series. Also, the electrical circuits of the stators are in series with the same currents in the windings. The rotor radius determines the slot area, hence the magnetic flux of the two stators. The flux has a significant effect on the machine produced torque and copper loss.

Other optimization parameters are the width of inner and outer stator teeth that determines the winding space and the loss and efficiency. The optimization goal is to maximize efficiency with respect to the constraints that are presented in Table 2.

For the mentioned objectives and constraints, the designed DMCPM machine has been optimized using the well-known procedure GA [25].

The initial and optimal values of the geometrical parameters are presented in Table 3 .

Table 2. The optimization constraints.

\begin{tabular}{cc}
\hline Parameter & Value \\
\hline Average torque & $>18.5 \mathrm{Nm}$ \\
Torque ripple & $<1 \%$ \\
\hline
\end{tabular}

Table 3. The optimization parameters.

\begin{tabular}{lcc}
\hline \multicolumn{1}{c}{ Parameter } & $\begin{array}{r}\text { Initial } \\
\text { value }\end{array}$ & $\begin{array}{c}\text { Optimal } \\
\text { value }\end{array}$ \\
\hline Rotor diameter $(\mathrm{mm})$ & 82 & 94.1 \\
Inner stator tooth width $(\mathrm{mm})$ & 3 & 2.97 \\
Outer stator tooth width $(\mathrm{mm})$ & 3 & 3.11 \\
\hline
\end{tabular}




\subsection{Optimization results}

Figure 9 shows the flux density distribution in which the tooth maximum flux density is about 1.1T. The back electromotive force and the cogging torque are presented in Figures 10 and 11, showing an increase of $11.7 \%$ in the back EMF and the cogging torque from $0.27 \%$ to $0.7 \%$ in the optimized machine. The higher

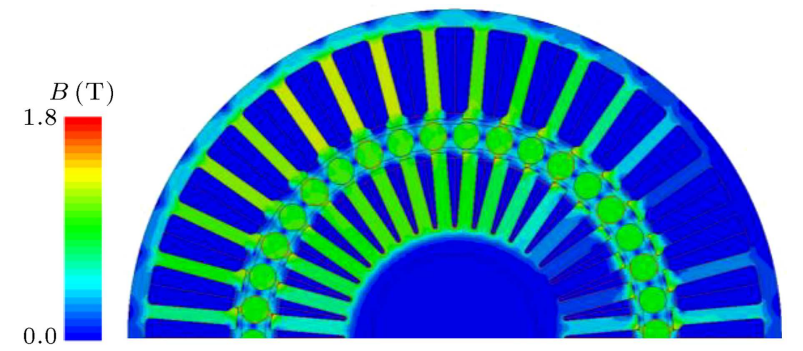

(a)

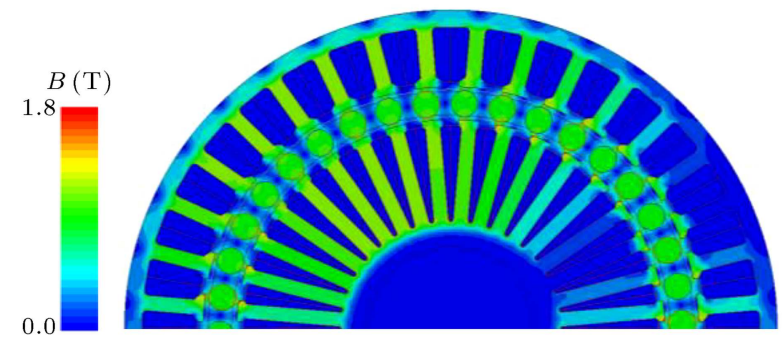

(b)

Figure 9. Magnetic flux density distribution: (a) Initial machine and (b) optimized machine.

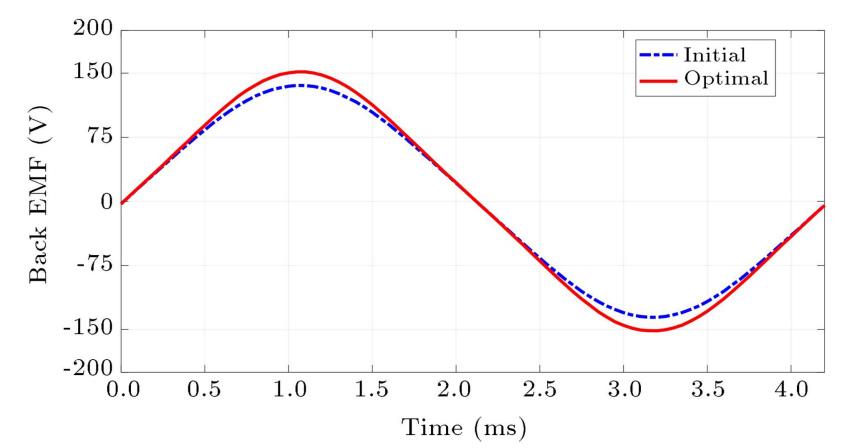

Figure 10. Back EMF.

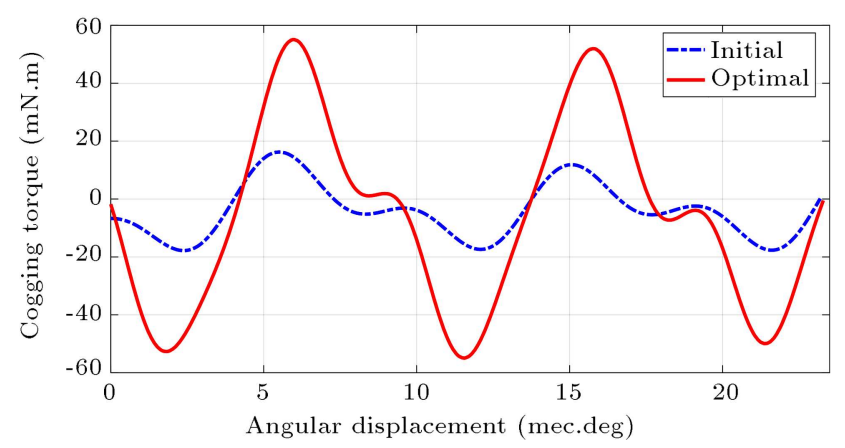

Figure 11. Cogging torque for initial and optimal designs. cogging torque results from the rotor radius increase, but still is considerably low.

Figure 12 compares the electromagnetic torque of the machines, where it shows a $2.2 \%$ increase in the average torque and a $42 \%$ decrease in the torque ripple. It is remarkable that although the cogging torque has increased, the total torque ripple in the optimized machine has improved.

Table 4 summarizes the initial and optimal design parameters. Besides, the comparison of the performance parameters, including efficiency, torque density, back EMF, and losses is made.

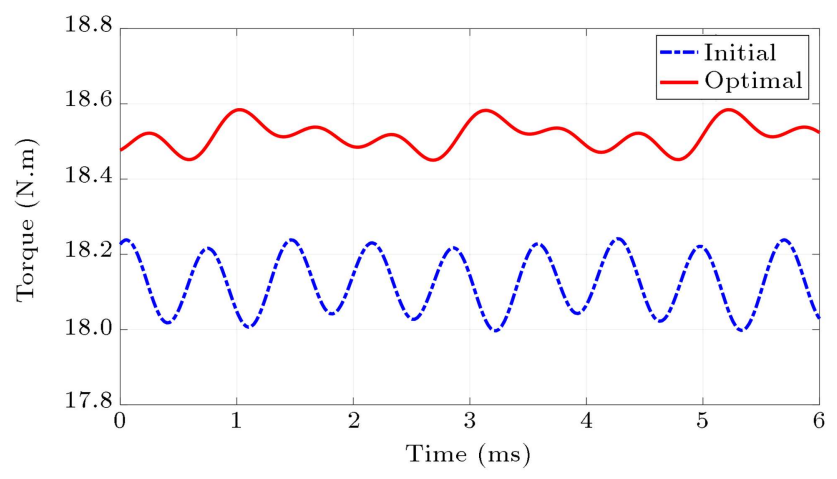

Figure 12. Produced electromagnetic torque for initial and optimal designs.

Table 4. The initial and optimal design parameters.

\begin{tabular}{lcc}
\hline \multicolumn{1}{c}{ Parameter } & $\begin{array}{c}\text { Initial } \\
\text { value }\end{array}$ & $\begin{array}{c}\text { Optimal } \\
\text { value }\end{array}$ \\
\hline Torque ripple (\%) & 1.37 & 0.8 \\
Cogging torque (\%) & 0.27 & 0.7 \\
Torque density (N.m./lit.) & 21.75 & 22.23 \\
Torque density (N.m./kg) & 3.895 & 4.012 \\
Average torque (N.m) & 18.12 & 18.52 \\
Efficiency (\%) & 91.8 & 92.4 \\
PM arc to pole arc ratio $(\alpha)$ & 0.81 & 0.7 \\
Machine weight (kg) & 4.651 & 4.616 \\
Core loss (W) & 31.2 & 33 \\
Copper loss $(\mathrm{W})$ & 95.9 & 86.49 \\
Mechanical power $(\mathrm{W})$ & 1427 & 1445 \\
Back EMF (V) & 135.7 & 151.8 \\
Wire area (mm $\left.{ }^{2}\right)$ & 0.95 & 0.86 \\
Phase resistance (ohm) & 1.1572 & 1.2833 \\
Torque per PM volume $\left(\mathrm{N} . \mathrm{m} / \mathrm{cm}^{3}\right)$ & 0.335 & 0.343 \\
Slot area (mm ${ }^{2}$ ) & 145.44 & 130.22 \\
Current density (A/mm $\left.{ }^{2}\right)$ & 5.5 & 5.5 \\
\hline
\end{tabular}




\section{Comparison with other topologies}

There are recently proposed DS-PMSM machines that have special advantages over previous versions. In this section, machines with similar power ratings are presented and discussed.

\subsection{Dual-stator spoke-type Interior PM Machine (S-IPMM) with spoke-type configurations using Phase-Group Concentrated Coil (PGCC) windings}

A dual-stator S-IPMM characterized by 24 stator slots $(S)$ and 26 magnet poles $(P)$ with PGCC windings was proposed in [14]. The two stators in the proposed machine are misaligned by one tooth width. Ferrite PMs are used which are arranged as a spoke-type array with the alternately reversing magnetization direction. Steel sheets of NSSMC 50H470 are utilized for the ferromagnetic parts of the machine.

When the rotor pole rotates to become aligned with the teeth of the stator, nearly all the PM fluxes corresponding to one phase group will flow into one air-gap to enhance the air-gap flux density. After the $\pi / 2$ electrical rotation, the same effects will occur in the other air-gap where the PM flux flows into two air gaps simultaneously. Therefore, a highly improved airgap flux density results in a higher subsequent torque than the conventional dual air-gap machines in which the two air gaps work independently.

\subsection{A novel dual-stator Vernier permanent magnet machine}

The proposed machine has two stators and a sandwiched rotor [15]. The outer stator is a conventional stator with three-phase windings and semi-closed slots, and the inner stator has an iron core and surface mounted PMs on it. The rotor has a consequent-pole structure with Halbach-array PMs.

The proposed machine can be observed as a superposition of two machines: single-stator PM machine (Machine I: the consequent-pole PM rotor and the outer stator) and a double-stator VPM machine (Machine II: the inner stator, the reluctance rotor, and the outer stator). Because of the self-shielding effect of the Halbach-array magnets, the rotor back iron is not needed for Machine I.

\subsection{Dual-stator consequent-pole permanent magnet Vernier machine}

In the configuration of the proposed machine [12], there are two stators and a sandwiched rotor. However, a key difference is that in the inner stator, as an alternative to surface-mounted PMs, consequent-pole PMs that reduce the PM volume are used. The machine can also be considered as a combination of two machines. The structure including an outer stator, sandwiched rotor, and inner stator iron teeth constitutes the termed Machine I, while the structure comprising an outer stator, iron teeth in the rotor, and the complete inner stator is named Machine II. In the proposed machine, Machines I and II are both dual-stator Vernier machines that increase the torque density.

The key novelty of the proposed topology is its working principle, where the flux of both rotor and inner stator PMs is modulated and the back EMF is induced in the winding of the outer stator.

\subsection{An optimized dual-stator machine with a diametrically magnetized PM}

The machine designed and optimized in the 3 rd section of this paper has been compared with other machines (A to $\mathrm{C}$ ) in the performances. Table 5 summarizes the results where the key parameters are torque ripple, cogging torque, torque density, and efficiency.

The torque density of machine D is 208-331\% higher, which means that when the same torques are desired for all machines, the active volume of machine D can be $52-70 \%$ smaller than that of machines A to C.

Table 5 shows that machine $\mathrm{D}$ contains at least $65 \%$ less cogging torque than other machines based on the FEM results.

The torque ripple of machine $\mathrm{D}$ obtained from the torque superposition of the two air-gaps is reduced by $73-95 \%$ compared to that of the other machines.

Efficiency is also a significant performance index. It is found that the efficiency of machine D is $2-20 \%$ higher than that of machines $\mathrm{A}$ to $\mathrm{C}$.

Totally, machine D exhibits significantly improved

Table 5. The comparison results.

\begin{tabular}{lcccc}
\hline \multicolumn{1}{c}{ Parameter } & Machine A & Machine B & Machine C & Machine D \\
\hline Torque ripple (\%) & 16 & 3.2 & 6.5 & 0.854 \\
Cogging torque (\%) & 4 & 2 & - & 0.7 \\
Torque density (N.m./lit.) & 9.7 & 6.1 & 8.7 & 20.226 \\
Torque density (N.m./kg) & 2.4 & 0.98 & - & 3.649 \\
Efficiency (\%) & 90.61 & 77.2 & 81 & 92.69 \\
Current density (A/mm ${ }^{2}$ ) & 5 & 5.2 & 5.2 & 5 \\
\hline
\end{tabular}


torque density, torque ripple and cogging torque, and acceptable improved efficiency.

\section{Conclusion}

This paper presented the air-gap flux density distribution analysis, design, and optimization of a dualstator machine with diametrically magnetized PMs. Upon conducting an analytical study of the machine and verification of the analytical solution, the machine was optimized for some output characteristics using artificial intelligence. Then, a quantitative comparison was made between the investigated machines with the aid of the 3D FEM. These comparisons demonstrated that the optimized understudy machine had at least $208 \%$ higher torque density, $2 \%$ higher efficiency, and lower pulsating torque.

The analyses verified that the optimized dualstator machine with a diametrically magnetized PM had significant improvements in electromagnetic performances; therefore, it is suitable for direct-drive applications.

\section{Nomenclature}

$B_{r} \quad$ Magnet remanent flux density

$B_{g} \quad$ Air-gap flux density

$\phi_{g} \quad$ Air-gap flux

$\mu_{0} \quad$ Permeability of free space

$r \quad$ PM radius

$k_{l} \quad$ Leakage factor

$J \quad$ Current density

$A_{m} \quad$ PM cross-section

$l_{m} \quad$ PM thickness

$O_{D} \quad$ Motor outer diameter

$N_{s} \quad$ Number of slots

C Cogging torque goodness factor

c Air-gap area coefficient

$g \quad$ Air-gap length

d Minimum air-gap length

$L \quad$ Axial length

$w_{t} \quad$ Tooth width

$k_{r} \quad$ Reluctance factor

$K_{w} \quad$ Slot fill factor

$A_{g} \quad$ Air-gap cross-section area

$\alpha \quad$ PM arc to pole arc ratio

$I_{D} \quad$ Motor inner diameter

$N_{C} \quad$ Smallest common multiplier

$P \quad$ Number of pole pairs

\section{References}

1. Zhao, W., Lipo, T.A., and Kwon, B. "Dual-stator twophase permanent magnet machines With phase-group concentrated-coil windings for torque enhancement", IEEE Trans. Magn., 51(11), pp. 1-4 (2015).

2. Cupertino, F., Leuzzi, R., Monopoli, V.G., et al. "Maximisation of power density in permanent magnet machines with the aid of optimization algorithms", IET Electric Power Applications, 12(8), pp. 1067-1074 (2018).

3. Vukotić, M. and Miljavec, D. "Design of a permanentmagnet flux-modulated machine with a high torque density and high power factor", IET Electric Power Applications, 10(1), pp. 36-44 (2016).

4. Asgari, S. and Mirsalim, M. "A novel dual-stator radial-flux machine with diametrically magnetized cylindrical permanent magnets", IEEE Trans. Ind. Electron., 66(5), pp. 3605-3614 (2019).

5. Feng, C., Jing, X., Bin, G., et al. "Double-stator permanent magnet synchronous in-wheel machine for hybrid electric drive systems", IEEE Trans. Ind. Electron., 45(1), pp. 278-281 (2008).

6. Mo, L., Quan, L., Zhu, X., et al. "Comparison and analysis of flux-switching permanent-magnet doublerotor machine with 4QT used for HEV", IEEE Trans. Magn., 50(11), pp. 1-4 (2014).

7. Kim, S., Cho, J., Park, S., et al. "Characteristics comparison of a conventional and modified spoke-type ferrite magnet motor for traction drives of low-speed electric vehicles", IEEE Trans. Ind. Appl., 49(6), pp. 2516-2523 (2013).

8. Dalal, A. and Kumar, P. "Design, prototyping, and testing of a dual-rotor motor for electric vehicle application", IEEE Trans. Ind. Electron, 65(9), pp. 71857192 (2018).

9. Wang, Y., Niu, S., and Fu, W. "A novel dual-rotor bidirectional flux-modulation PM generator for standalone DC power supply", IEEE Trans. Ind. Electron, 66(1), pp. 818-828 (2019).

10. Li, Y., Bobba, D., and Sarlioglu, B. "Design and optimization of a novel dual-rotor hybrid PM machine for traction application", IEEE Trans. Ind. Electron, 65(2), pp. 1762-1771 (2018).

11. Yang, H., Zhu, Z.Q., Lin, H., et al. "Comparative study of hybrid PM memory machines having singleand dual-stator configurations", IEEE Trans. Ind. Electron, 65(11), pp. 9168-9178 (2018).

12. Baloch, N., Kwon, B., and Gao, Y. "Low-cost hightorque-density dual-stator consequent-pole permanent magnet vernier machine", IEEE Trans. Magn., 54(11), pp. 1-5 (2018).

13. Kwon, J.W. and Kwon, B. "Investigation of dualstator spoke-type vernier machine for EV application", IEEE Trans. Magn., 54(11), pp. 1-5 (2018). 
14. Zhao, W., Chen, D., Lipo, T.A., et al. "Dual airgap stator- and rotor-permanent magnet machines with spoke-type configurations using phase-group concentrated coil windings", IEEE Trans. Ind. Appl., 53(4), pp. 3327-3335 (2017).

15. Gao, Y., Qu, R., Li, D., et al. "A novel dual-stator vernier permanent magnet machine", IEEE Trans. Magn, 53(11), pp. 1-5 (2017).

16. Gorginpour, H. "Design modifications for improving modulation flux capability of consequent-Pole vernierPM machine in comparison to conventional vernierPM machines", Scientia Iranica, 27(6), pp. 3150-3161 (2019).

17. Baloch, N., Khaliq, S., and Kwon, B.I. "HTS dualstator spoke-type linear Vernier machine for leakage flux reduction", IEEE Trans. Magn., 53(11), 8111104 (2017).

18. Baloch, N., Khaliq, S., and Kwon, B.I. "A high force density HTS tubular Vernier machine", IEEE Trans. Magn., 53(11), 8111205 (2017).

19. Zhu, L., Jiang, S.Z., Zhu, Z.Q., et al. "Analytical methods for minimizing cogging torque in permanentmagnet machines", IEEE Trans. Magn., 45(4), pp. 2023-2031 (2009).

20. Hanselman, D.C., Brushless Permanent Magnet Motor Design, McGraw-Hill, New York (1994).

21. Gieras, J., Wang, R., and Kamper, M., Axial Flux Permanent Magnet Brushless Machines, Springer-Verlag, New York (2008).

22. Zhu, Z.Q., Ruangsinchaiwanich, S., Chen, Y., et al. "Evaluation of superposition technique for calculating cogging torque in permanent-magnet brushless machines", IEEE Trans. Magn., 42(5), pp. 1597-1603 (2006).

23. Sadeghi, S. and Parsa, L. "Multiobjective design optimization of five-phase Halbach array permanentmagnet machine", IEEE Trans. Magn., 47(6), pp. 1658-1666 (2011).

24. Gieras, J.F., Permanent Magnet Motor Technology: Design and Applications, Taylor \& Francis Group, New York (2010).

25. Arslan, S., Gurdal, O., and Akkaya Oy, S. "Design and optimization of tubular linear permanent magnet gen- erator with performance improvement using response surface methodology and multi-objective genetic algorithm", Scientia Iranica, 27(6), pp. 3053-3065 (2018).

\section{Biographies}

Shahin Asgari (S'17) was born in Iran in 1987. He received the BS degree from the Kermanshah University of Technology, Iran in 2012 and the MS degree from the Amirkabir University of Technology, Tehran, Iran in 2015, both in Electrical Engineering. His research interests include design, analysis, and optimization of electric machines, renewable energy, and hybrid vehicles. He is currently with the Electrical Machines and Transformer Research Laboratory (EMTRL: http://emtrl.aut.ac.ir), Department of Electrical Engineering, Amirkabir University of Technology. Mr. Asgari attained some awards in national/international robotics competitions including AUTCUP and Khwarizmi Robotics Competitions.

Reza Yazdanpanah (M'14) received the BS degree from Shiraz University, Shiraz, Iran, 2003, the MS degree from the Isfahan University of Technology, Isfahan, Iran, 2006, and the PhD degree from Amirkabir University of Technology, Tehran, Iran, 2014, all in Electrical Power Engineering. He is currently an Assistant Professor at the Department of Electrical Engineering, University of Larestan, Lar, Iran. His research expertise and interests include "Electromagnetic Analysis and Design, Design and simulation of Electrical Machines \& Drives, Power Electronics, Power Systems Analysis, Applied Nonlinear Control, and Neural Networks".

Mojtaba Mirsalim (SM'04) received the BS degree in Double Major Electrical/Nuclear Engineering and the MS degree in Nuclear Engineering from the University of California, Berkley in 1978 and 1980, respectively, and the $\mathrm{PhD}$ degree in Electrical Engineering from Oregon State University, Corvallis in 1986. He is currently a Professor at the Electrical Engineering Department. His special fields of interest include design, analysis, and optimization of electric machines. 